\title{
The Time of Phantasy and the Limits of Individuation
}

\author{
Dieter Lohmar ${ }^{1}$ iD
}

Accepted: 30 August 2020 / Published online: 22 September 2020

(c) The Author(s) 2020

\begin{abstract}
Husserl is known to have oriented many aspects of his extensive analyses of phantasy around a contrast to perception: what phantasy and perception have in common, for example, is their intuitiveness; yet, while in perception something is encountered 'in the flesh,' in phantasy this experience is modified by its 'as if in the flesh' character. However, both in the majority of Husserl's reflections on phantasy and in much of the secondary literature on the topic, we find few further details concerning the difference between both modes of intuitiveness: 'in the flesh' and 'as if in the flesh.' In this paper, I draw on sources from Husserl's later work in order to get clarification on at least one important point of difference, namely the ways in which individuation and identity, that is, constitutions of individual and identical objects, clearly set apart phantasy from perception. As we will see, this requires an understanding of Husserl's account of objective time, and of the constitution of individual identical objects with their unique positions in objective time. After an introductory discussion of the meaning and the conditions of individuation in the methodical framework of phenomenology, I will lay out the different levels of the constitution of objective time $(1+2)$. In the second part of the paper, I will try to follow and explore one of Husserl's arguments that contrasts the constitutional performances involved in the constitution of phantasy objects with the individuation of real objects in objective time (3+4). The textual basis for this discussion is to be found in Husserl's last book, Experience and Judgement. In what follows, I will begin with a short discussion of the concepts of individuality, individuation, uniqueness and identity, and also ask why these issues may be of special interest for a phenomenologist who is investigating the phenomenon of phantasy.
\end{abstract}

Husserl is known to have oriented many aspects of his extensive analyses of phantasy around a contrast to perception: what phantasy and perception have in common, for example, is their intuitiveness; yet, while in perception something is encountered 'in the flesh,' in phantasy this experience is modified by its 'as if in the flesh'

Dieter Lohmar

Dieter.Lohmar@uni-koeln.de

1 Universität Zu Köln, Husserl-Archiv, 50923 Köln, Germany 
character. However, both in the majority of Husserl's reflections on phantasy and in much of the secondary literature on the topic, we find few further details concerning the difference between both modes of intuitiveness: 'in the flesh' and ' $a$ s if in the flesh.' In this paper, I draw on sources from Husserl's later work in order to get clarification on at least one important point of difference, namely the ways in which individuation and identity, that is, constitutions of individual and identical objects, clearly set apart phantasy from perception. As we will see, this requires an understanding of Husserl's account of objective time, and of the constitution of individual identical objects with their unique positions in objective time. ${ }^{1}$

There are questions that the title of my paper immediately raises: What is meant by 'individuation'? What might phantasy have to do with it? What makes an object unique? If we pose these questions from the perspective of phenomenological constitutional analysis, they turn into questions like the following: Which performances are 'necessary' for individuation, that is, which are eidetically tied to it? It is these kinds of questions that I will pursue in this article.

After an introductory discussion of the meaning and the conditions of individuation in the methodical framework of phenomenology, I will lay out the different levels of the constitution of objective time $(1+2)$. In the second part of the paper, I will try to follow and explore one of Husserl's arguments that contrasts the constitutional performances involved in the constitution of phantasy objects with the individuation of real objects in objective time $(3+4)$. The textual basis for this discussion is to be found in Husserl's last book, Experience and Judgement.

In what follows, I will begin with a short discussion of the concepts of individuality, individuation, uniqueness and identity, and also ask why these issues may be of special interest for a phenomenologist who is investigating the phenomenon of phantasy.

\section{The Problem of Individuation}

Usually we tend to associate concepts of individuation and individuality with persons. Persons are unique because of their unique history, and as a result of their 'personal individuation' in becoming the person they are. However, the uniqueness of persons is not the only case of uniqueness; it is not even paradigmatic. We also expect real objects in time and space to be individual and unique. As is the case with persons, the claim of uniqueness and individuality is not contradicted by the fact that real things also change in time. What's more, phenomenologists are not only interested in full-blown spatio-temporal objects, but also in 'objectivities' at lower levels of constitution. Thus, already in what Husserl calls 'experienced,' or 'lived' subjective time, we can detect low-level forms of 'individuality' riding on the distinctness of the sensually given, for example, the special shade of colour, the location in our sensual fields etc. However, as we will see below, individuation in

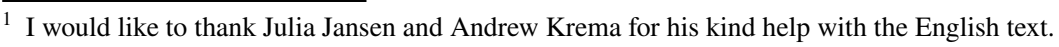


the full sense of the word can only be reached as part of the nexus of real objects in the objective time of the world.

In the 'natural attitude,' individuation is typically not problematized (we assume that the world is simply furnished with individual objects). Phenomenological research, on the other hand, certainly requires an account of individuation, namely a 'constitutive' account, which is in fact central to Husserl's analyses of time. In letters written around 1917/1918, and also in some of the Bernau Manuscripts, Husserl stresses the importance of this topic. ${ }^{2}$ In the methodical framework of phenomenology, 'individuation' names constitutive performances that let us experience objects as unique and identical. Of course, amongst such objects, we have to make a difference between 'temporal objects,' which are objects that carry time in their very sense (e.g., melodies or events), and other, spatio-temporal objects, which prima facie appear to have a simpler structure. After all, while melodies or symphonies remain 'the same' on a certain level of generality, each single performance of a melody is individual and unique, and its individuality is owed to the time and temporal flow of the performance as well as to individual interpretations and even flaws (which are material and sensuous qualities). Regardless of this distinction, however, whenever we are dealing with objects that we find similar, or that even 'look,' 'sound, etc. the same, individuation is what makes them numerically identical in different situations and allows us, for example, to recognize that 'this' is the same thing that was 'here' before. Thus individuation (constituting an object's uniqueness) in the full sense is dependent on the constitution of a world of things that are characterized by their place and their present sensuous properties, as well as by a history of their changes of place and changes of properties (paper turns yellow, a banana browns, a tree blossoms, the street becomes dusty, etc.).

I should shortly remind us of the specific way time is investigated in transcendental phenomenology. As is well known, the method of the transcendental reduction is designed to investigate the performances of consciousness that are necessary to reach a constitutional aim, and this research must be, as subject to the epoché that initiates phenomenological inquiry, completely independent from the presupposition that something exists or has causal properties. This transcendental analysis of constitution is no deductive or regressive-deductive argument (as in Kant's deductions), but it is an investigation of the eidetically necessary connections of 'performances of consciousness' (Bewusstseinsleistungen). An eidetic analysis reveals the necessary (apriori) connections between constitutional performances, and it usually reveals the systematic interdependences between founding and founded acts of consciousness. Thus understood, the special contribution of transcendental phenomenology is an

\footnotetext{
${ }^{2}$ Cf. Husserl's letters to Grimme 8.6.1918 (HuaDok III.3, p. 83f.; for a full reference to the Husserliana Dokumente, see the shared bibliography following the issue introduction), to Ingarden 5.4.1918 (HuaDok III.3, pp. 179-182), to Heidegger 28.3.1918 (HuaDok III.4, p. 129f.), to Weyl 10.4.1918 (HuaDok III.7, p. 287). In Hua XXXIII, the topic is treated in texts 16, 17, 19 (for a full reference to the Husserliana, see the shared bibliography following the issue introduction), and others, as well as in Beilage I in Husserl (1939) (henceforth cited as 'EU' with respective pagination, followed by the pagination of the English translation). See also Heidegger's short preface to the 1928 edition of Husserl's Lectures on the phenomenology of internal time consciousness this topic is mentioned (Husserl 1928).
} 
investigation, under the epoché, into the eidetic structures of the performances of our consciousness as they correlate with whatever objects in question. The main aim of the transcendental reduction is to avoid investigations that suffer from untested presuppositions, like the ones we find in a simple realistic approach to foundational problems, which the transcendental reduction reveals as problems of constitution.

If you take individuation as an example, then a realistic approach to the claim that we can have access to unique real objects seems very simple indeed, trivial even. This is so because it is a never-discussed presupposition of realism that real objects in the real world remain the same: this stone, my car, your beer etc. Sometimes we might have difficulties identifying things properly, especially if they are very much alike, for example my beer and your beer, but we trust that we will be able to solve this problem. In order to account for individuality and uniqueness, realists tend to rely on the basic properties of real objects themselves: They simply are like this; they are identical, and there is no question about it. And as long as we remain everyday realists, we all believe in this simple fact without question. ${ }^{3}$ Yet, there are some sceptic thinkers, such as Hume, who hint at the fact that in supposing objects to be identical, we are making a risky choice; for perceptually we always have only relatively similar sensible representations of a given thing, which continuously change, for example, with lighting conditions and perspective. In one perception it appears like this, in the next slightly different. If we start arguing as realists, we simply rely on the identity of the object itself and ultimately on the 'uniformity of nature,' which, as Hume pointed out, we can never find a valid argument for, and which thus remains a presupposition that we never doubt. Thus a 'realist' argument, simply relying on the alleged 'fact' that things remain the same, is of no use in the attempt to radically establish the possibility of identity and cognition.

Hume already indicated the kind of analysis that is useful in allowing us to understand our optimism in individuation and uniqueness: we should try to find out what the kinds of evidences we really have for identity, even if they turn out to be quite weak, and also recognize the unfounded optimism implied in our conviction concerning uniqueness. This is more or less the way Husserl's phenomenological investigations go in the case of individuation: they investigate the structures of constitutional performances that are necessarily involved in the claim that some object is 'unique,' or that it is 'individuated.' These investigations entail the following steps: our starting point is sensuous experience and what Husserl called 'the ABCs of constitution,' from lower to higher levels of constitution: first, we have to find out how the sense of time enters the stream of our sensuous experiences, what we might, on this first level, think of as the duration of sense data. This deepest level of constitution in inner time-consciousness gives the flux of sensibility a first sense of time, and it does so in virtue of the interdependencies of retentional, protentional, and impressional moments in inner time-consciousness. Then, we have to go to the next level of constitution where alike, or almost alike sensuous unities synthetically form homogeneous areas that demarcate other homogeneous areas with different qualities, and create something like Gestalt-fragments. We can find these syntheses of

3 In German we might say, it is 'selbstverständlich,' self-understood and taken for granted. 
homogeneity and heterogeneity in all fields of sensibility. ${ }^{4}$ Finally, in a third step of the $\mathrm{ABCs}$ of constitution, we discover the intentional apperception that allows us to interpret the Gestalt-fragments of the previously mentioned level as 'representatives' (Repräsentanten) of objects thus 'showing,' for example, the edges or frames of an object. And here we add to given objects also the sense of duration and the attribution of a location in objective time. So this third step is of utmost importance. But to be clear about it: In this short 'ABCs' of constitution, we do not find out how objective time itself is constituted, within which we ascribe positions to objects. This question is in fact quite difficult to answer on the basis of Husserl's texts because Husserl does not offer simple solutions but only sketches some important aspects of the constitution of objective time. ${ }^{5}$ Hence, in order to fully understand the phenomenon of individuation, and to learn from it for the purpose of better understanding phantasy, we have to take further steps.

\section{The Constitution of Objective Time}

Sometimes it seems to us as if we are simply 'watching' time pass by, but this is not as easy as it seems; for of course we cannot perceive or sense it in any way. The experience of time is a complex product of constitutional activities. There are at least two different important contexts for this constitutional process: first, there is the utmost 'now,' which entails everything that we are currently sensing and having intuitively in mind as a follow up of earlier phases of consciousness (retention). Husserl investigated this ultimate 'now' during the period beginning with his 1904/5 lectures on time constitution (Hua X) up until his Bernau Manuscripts of 1917/18 (Hua XXXIII). This context involves the presence of sensible givenness on the lowest level of constitution, viz. impression (later hyle), accompanied by retention, which is a conserving activity following sensual givenness (on the lowest level) or intentions (on a higher level).

The constitutional process is therefore based on this ultimate now, that is, on impressions mixed with retentions from former phases of our intentional life, retentions at different levels sinking-down in intensity and differentiation. And the first constitutional result of this lowest level is the duration of sensible givenness, which allows us to speak about sense data together with their duration. From this lowest level of constitution, higher-level performances develop in different directions, beginning with the unification of homogeneous sensible givenness in contrast to heterogeneous sensibility. This allows us to have something like lasting tones and shapes of homogeneous Gestalt-fragments in visual dimensions. By collecting and synthesizing these Gestalt-fragments, we start to form, out of this sensible

\footnotetext{
4 See Husserl's investigations of prominences (Abgehobenheiten) in his Analysen zur passiven Synthesis (Hua XI, §§ 28-29).

5 In his first attempt to solve the problem-this was in the reworking of the lectures from 1904/1905 in September 1917-Husserl tries to connect individuation to the unique way of presentation in sensibility (see Lohmar 2006, pp. 55-77).
} 
raw material, intentional objects in time and space. All the while, it is important to remember that all of these activities are performed within a single moment, and that the next object of our attention is already showing up. In the case of specific time objects, like melodies, we unify a series of intentional objects to a new Gestalt of a higher order. The same happens in series of different intentional objects that entail events, change, or movements of things. These specific time-objects already entail 'short-term duration' in the flux of change, but none of this gives us already a sense of objective time. Husserl calls this experienced time 'subjective time' and searches for its possible connection to what we usually and in our everyday attitude call objective time.

Keep in mind here that phenomenologists have no recourse to something like Kant's theory of time, on the basis of which you may assume that these short-term unifications into episodes already somehow stand 'within' the all-encompassing objective time. For phenomenologists, this model of a form that was there before, only waiting for us to fill it with sensual content, is nothing more than a presumption. What phenomenologists can do is to clarify how this idea of an encompassing time is born out of some process of unification of smaller units we are able to constitute. And in the search for this handicraft picture of the constitution of time and space, we are just at the very beginning. ${ }^{6}$ When we leave the realm of the 'ultimate now' and the 'short-term' duration of time objects in subjective time, what we retain from this series of constitutional processes are associative connections of ideas of these objects and events that we might call 'memories' in the form of short episodes. The next step of the constitution of an objective time therefore asks for a synthetic unification of these memorized episodes. And the result of this unification is a time that also exceeds the sensible givenness of things and leads beyond the whole of my individual experiences in the past.

Now we turn to the process of synthetic unification of time on further levels of time-constitution. We begin already on the level of subjective time, that is, with appearing sensual givenness, like color spots, tones, or Gestalt-fragments that are given together with their duration. Movements and change are already characteristics of objects, due to an intentional apperception that makes them objects of their own. Also, on this level, the events are ordered in successions on the level of subjective time, and this order is sedimented in a merely associative way that makes them also reappear in what we experience as episodic memories. These episodes are internally ordered. That means they have a kind of starting point, end point, and inner order within the episode. The internal order of the episodes must somehow be 'fixed' in performances of our consciousness - but, at this level of constitution, it is unclear how.

\footnotetext{
6 There is an important parallel to this puzzle-model of understanding objective time in Husserl's investigation of the constitution of space to be found in Hua XVI. There too, he does not believe in a prefigurated form of objective space, but tries to figure out how we constitute the idea of this big encompassing space 'bottom up,' out of small experiences, e.g., by seeing and touching things, keeping them for a while, and moving my body first involuntarily and then willingly between intuited things.
} 
We can find some hints about the mode of this 'fixation' in Experience and Judgment (cf. EU, pp. 237/201f.; Lohmar 1998, ch. III, esp. 6b, c, 8a). In Husserl's latest book, the analysis of the different activities of our consciousness and their interwovenness in a kind of history has become the most effective tool of genetic phenomenology. To "keep something in one's grip" (Im-Griff-Halten) is an activity of the subject (cf. EU §23a, pp. 116-123/106-112). Thus the assertion of a starting point in the perception of an object and the internal ordering of the respective story of perception belong both to the class of characteristics that we are aware of only by repeated perceptions and pre-predicative experiences. Husserl sometimes calls this "implicit knowing" (Kenntnis) — and speaks of an awareness of "lasting" resp. "habitual knowledge" (erworbene bzw. habituelle Kenntnis, cf. EU, pp. 137 f./122f.) - but this falls still short of being knowledge in the full sense (cf. Lohmar 1998, ch. III, 4-7). ${ }^{7}$

Now we go back to our analysis of the assertion of an individual point in time. We know that we have seen the object at this place in this perspective, and it connects associatively with other events that were 'nearby,' later or earlier, and so on. The problem is that we are not yet able, in virtue of this activity, to make up a precise objective order of all these upcoming episodic events. To address this difficulty, let us consider an example that may be a kind of paradigm for this problem: If we look at unordered photos taken during a vacation some years ago, then each of the photos evokes a small story that is internally well ordered. And yet, we know that it is sometimes very difficult to take the next step towards the constitution of an encompassing history (the vacation as a whole). We remember each single episode when we look at the respective photo, but we cannot put all the photos into an objective order along one time-line (cf. Hua XXXIII, p. 298).

Most of us are very familiar with this phenomenon. We commonly have different and separated memories of episodes (internally well-ordered, in the sense of 'first this happened, then this happened'), while the exact order between these distinct episodes is undetermined. ${ }^{8}$ If we want to generate an objective order of these episodes, then we have to take a new synthetic step. This specific step-in which internally ordered episodes are synthetically unified in the new form of an objective order in linear time-is the theme of text 16 of the Bernau manuscripts (Hua XXXIII, pp. 292-295). This new synthesis results in a (hypothetical) draft of an objective order.

The internal order of the remembered subjective moments of time cannot really help in this process because all 'before' and 'after' in this subjective dimension can only help form an associative order internal to this episodes. And even though the episodes may overlap and thus form a chain of a longer extension, the sense of this ordering cannot be identified as linear, one-dimensional time. Husserl attempts to positively characterize this synthetic step from subjective time to objective time, but

\footnotetext{
7 It may, however, become knowledge. For example, it might turn into knowledge about the order of events in predicative terms if I use the associative order-one event points back or forth to anotheras the basis for a new running-through the episode in a new and higher-order attitude, geared towards knowledge about the order of events.

${ }^{8}$ In German, sometimes we speak of small 'shreds of memories' (Erinnerungsfetzen).
} 
does so in a truly surprising way. He describes the internally ordered episodes in memory as many "lines of pasts" (Linien von Vergangenheiten) (Hua XXXIII, p. 293). Using the model of a plane, Husserl describes these internally ordered lines as lying "side by side" in a "two-dimensional continuum" (plane) and not yet in the "one-dimensional linear continuum" of the "one time" (ibid.). ${ }^{9}$ This is the synthetic step currently missing. Thus, to constitute such a one-dimensional order, we have to make a kind of guess about the objective order of all these episodes (but this remains only my own hypothesis).

What Husserl calls the 'universe of pasts' are the many 'lines of pasts' in our memory of objects that form subjectively ordered stories, or episodes of earlier perceptions. Each perception and each event forms a 'line of past;' that is to say, each of them has 'its own past.' Even if some of these pasts are overlapping and link up in longer episodes (for example, going to the theater, meeting with friends, drinking a beer during the intermission, etc.), they cannot, by this process, make up the whole linear past. Turning back to the example of the past vacation, we can see the plausibility of Husserl's diagnosis that we have only a 'universe of pasts' coming up in our memories in the form of episodes, which are not yet externally ordered (cf. Hua XXXIII, p. 293). Only if we are able to generate a big 'map'-about how all these lines of past belong together - these 'lines of past' may connect and form a linear "system of pasts" (Hua XXXIII, p. 294). Each of them shows an object in a certain situation, and thus leads back to a first founding in originary givenness and to the constitution of a starting point in this episode. ${ }^{10}$ Yet, we have to also keep in mind that we can get that big 'map' wrong, and that other persons may challenge our ordering. Now we can see that this model calls for at least three levels of time-coordination.

Here is my brief summary:

1. There are many unified 'lines of pasts' lying 'side by side' on a two-dimensional field. ${ }^{11}$ Each line is extended, continuous, and internally ordered. The elements of subjective time, i.e., the memorized episodes, are, on a first level, ordered by means of association, but they do not connect with one another in an objective linear 'big system' of time. They somehow remain lying 'side by side' until we begin to make efforts to coordinate them in a linear time-line.

2. The next step is the synthetic unification of all these lines to a linear and onedimensional system of time - a synthesis that I can do on my own. The result is quite independent from the first-level order in episodes. And we know that we may also err in this second step of time-coordination; for with it, I can only reach

\footnotetext{
${ }^{9}$ I cannot discuss here the challenging question concerning the different tempi of subjective time-experience, which may reveal themselves in a 'stretching' or 'condensing' of experienced time. There may be a way of analyzing this effect in becoming attentive to the different types of protentions (cf. Lohmar 2003, pp. 154-167).

${ }^{10}$ Husserl mentions concerning these different pasts "dass sie alle zurückführen auf den einen Prozess der ursprünglichen Präsentation, dass jede eindeutig zugeordnet ist in einem ursprünglichen Jetzt mit seinem Inhalte" (Hua XXXIII, p. 293).

11 We might think of the possibility that pasts may overlap, but this is not our common experience.
} 
a kind of objective-order-for-me. Others may correct my mapping, especially because the extension of my solipsistic-objective time remains limited to the arrangements of my own memories. I cannot cover the whole of my life since, for example, first-hand memories of my first years may not be available to me. Nonetheless, if Husserl is right, my first solipsistic draft is the basis for all higherorder coordination in objective-intersubjective time.

3. As soon as I establish this objective-time-for-me, it becomes evident that there is another step of intersubjective coordination that remains to be done: Other people may correct my first draft or hypotheses because each person has his or her own objective-order-for-him. In this coordination of the third order, we have to integrate other people's various drafts into our 'map,' with the help of communication, so that we may collectively reach an intersubjectively-objective order of time, an order-for-us-all.

And yet, up to now, the performance of the third level of intersubjective ordering is still underdetermined in at least two regards. (1) We immediately realize that in this communicative ordering, not every person is allowed to decide and have a say. ${ }^{12}$ The contribution of the third level of coordination is not at all exhausted by some corrections to our solipsistic draft because it can exceed the realm of my own memories. The belief in the reliability of other people's information concerning shared memories opens up a new source of information about the encompassing time of my community: people whom we consider 'reliable' in this regard, who therefore are granted a say concerning objective-intersubjective time, add to and even fill-in big gaps of my past. In this way, we arrive at a concept of intersubjective historical time, which has margins that can only be filled in by mythical tales about ancient civilizations and the origins of mankind. And yet, this sense of time remains within the confines of finite time, while we should also mention that-as a special variant of the intersubjective-objective time-we might borrow idealizations of physics concerning objective time, conceiving it as infinite and homogeneous. Together with the same idealizations in the dimension of space, we thus arrive at the specific idealizations of the modern natural sciences, and hence at physical time and space.

\section{Identification and Individuation in Objective Time}

Let us come back to one of the questions of individuation we started with: Two equal objects are given to us: How can we make a well-founded distinction between them, and how are they to be identified? Husserl's suggestion is: If I think of an individual in the full sense, I have to insert this object into a full history of its change and movements in space and objective time. This 'insertion' into an objective order of time is necessary to have an individual at all. This does not address the empirical

\footnotetext{
12 This performance, based on communication, is shortly discussed in EU, pp. 188 f./162 f. Some of the problems of intersubjective constitution of time are also discussed in the late C-Manuscripts of the years 1929-34 (see HuaMat 8; for a full reference to the Husserliana Materialien, see the shared bibliography following the issue introduction).
} 
difficulties of really identifying the object, but only names a principal performance of 'adding' a certain sense to the object, namely the sense of uniqueness. We can see this in a thought experiment: Think of an everyday object, like a cup, a book, or a car. I use it, but many other people also use similar objects. If I am trying to recognize such an individual object as the same, I may err or have difficulties performing this identification, but these empirical questions do not touch upon our topic of basic necessary intentional performances. For example, if I am searching for my blue car in a big parking lot, it can easily happen that I take the wrong car for my own. To find out which car is the right one, I have to re-perform the history of movements and events that started this morning when I came into the parking lot: I passed by the entrance, then turned left where there was a truck blocking the road, then I turned right, etc. I can make mistakes in the reconstruction of this past; maybe I weave events of past days into my reconstruction. Regardless, I have to insert this object into some full history of its changes and movements. This entails the idea of a unique individual. It is the transcendental condition of individuation, and it does not depend on the empirical question of whether I am successful in my attempts or not. This particular addition of sense to a real object is an intentional performance that gives my search a good sense at all.

Therefore, If I believe that I have at last found the right object, I have already performed a synthetic unification of the second order of my episodic memories of events that somehow drop into my mind. I have inserted this object into a plausible story of its change and its movements. What does the element of 'plausibility' mean here? Plausibility in this context applies to our knowledge about motivation and causal effects in the world (and their related probability). To stay with our example: If I see a blue car in the parking lot at the place where I might have left it in the morning, but there is a certain scratch at the left door that is missing, I am very sure that this is not my car. My being sure depends on everyday knowledge about causality and motivation: In a parking lot, such a scratch could be added without my knowledge, but it will never vanish without my knowledge. ${ }^{13}$ We see, then, that even the identification of such everyday objects depends on an extended knowledge of the world and of its possible changes and movements in it, and even of their respective probability. One might object that this is an example of everyday casuistry and that it seems impossible that such trivial things can contribute to such a deep performance as individuation, but this is nonetheless exactly what we discover in these analyses. $^{14}$

All this shows that we can perform individuation in the full sense only in objective time (of the first or second order) because all our considerations to insert an object into a plausible story of its change and movements rest on objective time as well as on our knowledge of causality, motivations and movements etc. In the end,

\footnotetext{
13 'Never' might be too strong. At least I can imagine that my car was brought into a repair shop and that the scratch was fixed there, but even then I am very sure that no one beside myself would pay for this.

14 For example, when I recognize a long lost friend, I will generally identify him because of his similarity with the one I knew long ago, but I will dismiss such identification if he still looks twenty years old. In this case my apperception changes from identity to mere similarity.
} 
we have to employ quite comprehensive knowledge of the world; beside that, we can never really fulfill the task of individuation completely. Ultimately, individuation always rests on localization in the spatial world, the localization in objective time, and a world of commonly shared facts (cf. EU, pp. 218f./186). So it turns out that seemingly trivial 'relations of facts' belong to the ultimate basis for individuation and for the establishment of interrelations between individual objects (cf. EU, pp. 216/185). The 'short history' of a 'line of past' in an episode of perception, or of some event, only leads to a kind of proto-individualization in a subjective and associatively ordered frame.

Husserl reaches a similar result in paragraphs $\S 39-40$ of Experience and Judgment, in his analyses of the time of phantasy. As he points out there, the objects of my phantasies stand only in incoherent and disconnected times ("Zusammenhangslosigkeit"). Husserl thus concludes that "individuation and identity of the individual, as well as the identification founded on it, is possible only within the world of actual experience, on the basis of absolute temporal position" (EU, pp. 203/173). However, objectivities of phantasy "lack absolute temporal position, and so they also cannot have a temporal unity among themselves, a unique temporal order like the objects of perception" (EU, pp. 198/170). ${ }^{15}$ Real objects and real events, by contrast, do have an unambiguous position in objective time and space to one another. One is earlier than the other, and they both have a unique position in time; they are enduring. Phantasy events do have a certain duration, but, according to Husserl, this is only a quasi-duration, which cannot be connected with objective time. We cannot say that one phantasized object or event is earlier (or later) than an other, or earlier (or later) than a real one. Objects and events in phantasy do not have a unique location in time ${ }^{16}$ because the coordination in unique relations of 'before and after' does not belong to the sense of phantasy-objects. In our apperception of phantasy objects, we simply do not perform such a 'locating activity.'

\footnotetext{
15 The materials that were used to compose these sections of Experience and Judgment originate from the 1917/1918 period of Husserl's analysis of time-constitution that are better known as the "Bernau Manuskripts." Until 1934 Husserl was optimistic about the possibility that his other assistant Eugen Fink would prepare a compilation of the Bernau Manuscripts together with him. That hope is lost after Husserl realizes that Eugen Fink, in spite of great efforts, was not able to do it (see the letters from Husserl to Fink 6.3.1933 and 21.7.1934 in HuaDok III.4, pp. 90-94). However, parts of these manuscripts dedicated to the time of phantasy, and also to individuation in objective time, were still in the hands of Ludwig Landgrebe who prepared Experience and Judgment. In the meantime Landgrebe had worked out a typescript under the title "Wirklichkeit und Phantasie. Untersuchungen zum Problem der Individuation" (cf. Ms. L II 11, a carbon copy of M III 3 VII). This typescript ist based on originals in shorthand written 1918 in Bernau and is incorporated in $\S \S 38 \mathrm{ff}$. of Experience and Judgment. Using this material from the Bernau Manuscripts, on the origin of individuality, in Experience and Judgement marks a change in Husserl's plans to publish the manuscripts by themselves, and it also conflicts with the declaration that he was not to present a theory of individuation in this book (cf. EU, pp. 203/173 f.; cf. Lohmar 1996, pp. 31-71).

${ }^{16}$ Husserl points out that they have "no temporal position in relation to one another" (keine Zeitlage zueinander), one is not earlier or later than the other, "the centaur which I now imagine, and a hippopotamus which I have previously imagined, and, in addition, the table I am perceiving even now have no connection amongst themselves;" and "the centaur is neither later nor earlier than the hippopotamus or than the table which I now perceive" (EU, pp. 196/168).
} 
An exception to this is a continuous phantasy story like a novel. In the framework of a uniform and continuous fictional story, objects of phantasy do have quasiduration, and also quasi-location in the quasi-time of this special tale or phantasy. For example, it takes some time for Hänsel und Gretel to pass through the forest and reach the witch's house. Yet, this quasi-time misses the real and proper location in objective time, and it will only be constituted under the conditions of a continuous story to which we subscribe. Here another important aspect connected to the influence of intersubjective constitution becomes relevant: It makes a difference whether it is only me who 'lives' for a while in the story told, or whether others also subscribe to it. In such continuous tales we might even identify persons and objects on the conditions that are presupposed in the tale: We can then 'quasi' speak of the 'same' Gretel who shows up later in a different scene, or in a movie based on the tale, etc.

Thus we arrive at the astonishing statement that objects of phantasy are generally not individuals and cannot be individuals in the full sense, even though we have to mind the important exception of the objects arising in phantasies that do form continuous phantasy narratives, or fictions. ${ }^{17}$ Only in continuous and connected stories will we find a kind of 'bond' between the events of the story; without it, we cannot. ${ }^{18}$ Even if the objects of disconnected phantasies are very similar to the point of being indistinguishable, we can neither speak about individual identity nor about non-identity in this cases (cf. EU, pp. 199/170). Thus even if we imagine perfectly indistinguishable objects in disconnected fantasies, they can neither be 'the same' object, nor can they be, in the proper sense of the word, 'different' objects. In these cases we can simply not know anything about their individuality, and even when we do in a sense (because a unifying story is available to us), then it is only a 'quasiidentity,' precisely because it is based merely on commonly accepted stories we have been told.

Again, in unconnected phantasies, there are only unconnected quasi-times, and there is no basis for identification or making differences, they lack an absolute temporal position: "Objectivities of imagination lack absolute temporal position" (EU, pp. 198/170), ${ }^{19}$ even though it is possible to invent a continuous story and to (quasi-) connect the unconnected phantasy events and objects, thereby giving the fictional objects a quasi-uniqueness in this story. This possibility notwithstanding, connection and identity do not belong to the essential traits of phantasy objects. ${ }^{20}$

\footnotetext{
17 They are not different from each other in the sense in which real objects are already different due to their location in time and space; they are not differentiated "qua individual object" (EU, pp. 197/169).

18 If there is no connection then there is no identity nor individuality of phantasy objects ("it is impossible to speak of several objects or even of one and the same object represented repeatedly" (ibid.).

19 There is an astonishing consequence for all objects of commonly shared tales about the most important objects of religion: Gods do not have the same kind of identity like real things, they only have a quasi-identity due to a commonly shared story.

20 As Husserl puts it: "Such a possible constitution of unity is external to the essence of imaginings [Phantasien]" (EU, pp. 198/170), i.e., connection and uniqueness do not belong to the essence of phantasies.
} 
Only in objective time do real objects have identity and uniqueness. This is independent from the kind of objective time, whether we mean 'objective-timefor-me,' on a first level of objective unification, or 'objective-intersubjectivetime-for-all,' on a second level of objective unification that we can only constitute together with others. Husserl states that the one time is the form, and the one and only form of individual objects. Objects are given to an ego first in unconnected sensible intuitions (Anschauungen), that is, in perceptions and memories (cf. EU, pp. 192/165). It is obvious that it is enough for the possibility of individuation to think of real objects in the objective-time-for-me constituted by myself alone. However, Husserl, in Experience and Judgement, makes a clear differentiation between two types of objective time. Objective-time-for-me is extended by the process of understanding others in empathy: "In empathy an objective, intersubjectively common time, in which everything individual in lived experiences and temporal objectivities must be capable of being ordered, is constituted" (EU, pp. 192/165). Thus individuation is also possible on the higher level of an objective-intersubjective-time-for-all.

Now we might say that there is another important factor for our ability to identify objects as one and the same: If objects are very similar, or appear perfectly 'alike,' then it is often very difficult to tell them apart, and as a consequence, it is difficult to identify with certainty one of these objects as the same. However, this is not really a substantial difference: we generally need detailed knowledge about the history of objects' movements, and their changes in time, to identify real objects. This seems to be a very mundane insight, but we have already seen that in our conviction that something is real, there is one crucial hidden presupposition, and this presupposition is not empirical at all. It is a sense-element that we add when taking an object as real, and do not add when taking an object as an object of phantasy. Due to this sense-element, it is not so important for a real object whether it is easy or difficult to identify, and to recognize on another occasion. This is only an empirical problem. The most important sense-element is an intentional performance: To take an object as something that keeps its identity in a history of change and movements. Therefore even for objects that are very unique and special in their appearance, the task of identification can only be solved if we have performed the intentional performance of adding the sense of individuality in these cases before. This is a transcendental argument, not an empirical observation.

Even if we tend to argue along more sceptical lines, it is obvious that even a rather unique appearance cannot exclude the possibility that a perfect look-alike will suddenly show up. This is true for artefacts as well as for humans. Thus the principal argument is that identification of objects always only has relative certainty. Hume already demonstrated this in his Treatise, and we only have to strengthen his argument slightly to see that we only have perceptions of objects that appear relatively similar in our surrounding world, where they are usually to be found-and on this weak ground we commonly judge that they are identical. For better or worse, this is our only way to the identity of real objects. 
Funding Open Access funding provided by Projekt DEAL.

Open Access This article is licensed under a Creative Commons Attribution 4.0 International License, which permits use, sharing, adaptation, distribution and reproduction in any medium or format, as long as you give appropriate credit to the original author(s) and the source, provide a link to the Creative Commons licence, and indicate if changes were made. The images or other third party material in this article are included in the article's Creative Commons licence, unless indicated otherwise in a credit line to the material. If material is not included in the article's Creative Commons licence and your intended use is not permitted by statutory regulation or exceeds the permitted use, you will need to obtain permission directly from the copyright holder. To view a copy of this licence, visit http://creativecommons.org/licen ses/by/4.0/.

\section{References $^{21}$}

Husserl, E. (1928). Edmund Husserls Vorlesungen zur Phänomenologie des inneren Zeitbewusstseins. Jahrbuch für Philosophie und phänomenologische Forschung, IX, pp. 367-490, ed. with an introduction by M. Heidegger. Halle: M. Niemeyer.

Husserl, E. (1939). Erfahrung und Urteil. Ed. L. Landgrebe, Prag: Academia.

Husserl, E. (1973). Experience and Judgement. Trans. by J.S. Churchill and K. Ameriks, Evanston: Northwestern University Press.

Lohmar, D. (1996). Zu der Entstehung und den Ausgangsmaterialien von E. Husserls Werk Erfahrung und Urteil. Husserl Studies, 13(1), 31-71.

Lohmar, D. (1998). Erfahrung und kategoriales Denken. Dordrecht: Springer.

Lohmar, D. (2003). What does protention "protend"? Remarks on Husserl's analyses of protention in the Bernau Manuscripts on time-consciousness. Philosophy Today. Issue Supplement: 154-167.

Lohmar, D. (2006). Konstitution der Welt-Zeit. Die Konstitution der objektiven Zeit auf der Grundlage der subjektiven Zeit. In: Passive Synthesis and Life-world. Sintesi passiva e mondo della vita, ed. by A. Ferrarin (pp. 55-77). Pisa: Editioni ETS.

Publisher's Note Springer Nature remains neutral with regard to jurisdictional claims in published maps and institutional affiliations.

${ }^{21}$ For full references to the Husserliana, Husserliana Materialien and Husserliana Dokumente see the shared bibliography at the end of the introduction to the special issue this paper is part of. 